\title{
XII. L'ORIGINE DES ÉLECTEURS ET DU COLLÈGE ÉLECTORAL
}

\author{
1. L'origine des électeurs et du collège électoral \\ vue par un auteur français au milieu du XVIII' siècle
}

Les auteurs de langue française sont parfois hésitants quand il s'agit de définir l'origine des électeurs et du collège électoral; or, il faut bien admettre avec Le Coq que l'»Origine [même] des Electeurs [...] est assez incertaine «', ou du moins qu'elle le fut longtemps. Si la recherche historique a entre-temps apporté les précisions nécessaires ${ }^{2}$, il faut concéder que l'état des connaissances fut pendant longtemps bien maigre, même chez les auteurs allemands des XVII et XVIIIe siècles. Pourtant, il est surprenant de trouver encore au milieu du XVIII ${ }^{e}$ siècle des auteurs qui ne renoncent pas complètement à la légende de l'établissement des sept électeurs par Grégoire V. Si l'on a à juste titre reproché à la curie romaine de recourir encore à cette légende au début du XVII siècle $^{3}$ (et encore la papauté avait-elle intérêt à la perpétuer pour affermir le droit d'ingérence qu'elle réclamait dans tout ce qui touchait à l'élection impériale!), on en trouve encore quelques vestiges en France, au siècle des Lumières. En 1748, Le Coq affirme en effet à propos de l'origine des électeurs: »Quelques Auteurs l'ont placée sous l'Empereur Othon III. \& sous le Pape Grégoire V. D'autres avancent avec quelque probabilité, qu'en 1002. le même Pape, parent d'Othon, qui se trouvoit sans postérité, nomma les Electeurs«. Si Le Coq ajoute encore foi à l'idée de la création des électeurs par Grégoire $\mathrm{V}$, ou la considère du moins comme probable, il n'en tire toutefois pas les mêmes conséquences que l'Église, et limite aussi la portée de ses propos en admettant qu'»il est cependant certain que depuis l'élection de ce Prince, quelques Empereurs furent élus par d'autres Princes que les Electeurs d'aujourd'hui, \& d'autres, par tous les Etats assemblés; d'où il résulte, qu'il est assez vraisemblable de fixer l'époque de leur création, dans le tems, ou immédiatement avant le grand Interrégne «. On se rapproche donc de la période exacte de la véritable origine du collège électoral, que Le Coq considère comme formant »dans toutes les affaires de l'Empire, un Corps qui est toujours total, indivisible, pur \& simple, légal \& subsistant par lui-même perpétuellement $\aleph^{4}$.

Or, quelle était l'opinion générale des auteurs français ou de langue française à l'égard du problème de l'origine des électeurs? Avant d'examiner les connaissan-

${ }^{1}$ LE COQ, Traité, p. 171.

2 Cf. BeCKER, Kurfürstenrat.

${ }^{3}$ Cf. Georg LUTz, Roma e il mondo germanico nel periodo della Guerra dei Trent'anni, dans: Gianvittorio SIGNOROTTO, Maria Antonietta VISCEGLIA (dir.), La corte di Roma tra cinque e seicento »teatro« della politica europea. [Atti del Convegno Internazionale di Studi (Roma, 22-23 marzo 1996)], Rome 1998 (Biblioteca del Cinquecento, 84), p. 425-460.

${ }^{4}$ LE COQ, Traité, p. 171. 
ces dont disposaient à l'époque les auteurs français, il faut d'abord rappeler l'état actuel de la recherche au sujet de l'origine des princes électeurs et du collège électoral. En effet, cette question constitue l'un des problèmes les plus difficiles du droit public allemand. Après qu'Onofrio Panvinio, un auteur italien, eut proposé la bonne solution dès le XVI $\mathrm{X}^{\mathrm{e}}$ siècle, des idées erronées persistèrent néanmoins jusqu'au $\mathrm{XX}^{\mathrm{e}}$ siècle. Il faut concéder que, au XVII' siècle, même des juristes allemands professèrent encore des hypothèses qui avaient pourtant été invalidées dès le siècle précédent. D'autre part, il paraît également important de replacer la discussion des auteurs français sur l'origine des électeurs dans son contexte européen. En effet, le premier livre français consacré à ce sujet fut une traduction de l'italien. Après un état des lieux résumant les connaissances actuelles, il est donc essentiel d'analyser les origines italiennes de la littérature française sur les électeurs de l'empereur ${ }^{5}$. Ensuite, nous examinerons les idées des auteurs français en particulier dans la deuxième moitié du XVIIe siècle, puisque c'est à cette époque que les connaissances des juristes allemands devinrent beaucoup plus précises ${ }^{6}$.

${ }^{5}$ Nous avons étudié cet aspect de manière plus détaillée dans BraUN, Ein italienischer Blick. Pour la documentation des résultats qui seront présentés dans les paragraphes suivants, cf. cet article (avec une bibliographie des publications récentes des médiévistes concernant l'origine des électeurs) et BECKER, Kurfürstenrat.

${ }^{6}$ Au sujet des opinions qu'on peut détecter dans les documents diplomatiques français concernant l'élection impériale, surtout au XVIIIe siècle, cf., par exemple, le grand »Mémoire sur l'élection des Empereurs« et »sur la part que la France a prise en différens tems à l'élection des Empereurs«, 2 vol. (AE, MD All. 1 et 2), »Envoyé à Monseigneur le Comte d'Argenson le 3 février 1745 « et "Envoyé à Monseigneur le Marquis de Puyzieulx le 23 aoust 1750 « (vol. 1, fol. 4); Le Dran a signé la préface (ibid., fol. 5-5'). Le premier volume concerne la période allant de Charlemagne jusqu'en 1713, le volume II la première moitié du XVIII ${ }^{e}$ siècle (1714-1733). Cf. également le »Mémoire sur la part que la France a pris[e] en différens tems à l'élection des Empereurs. Et sur les mesures prises par le Roy Louis XIV pour obtenir la dignité impériale« (AE, MD All. 7 fol. 3-274'); ce mémoire concerne la période qui va de 1519 jusqu'en 1658; un »Abrégé« de ce mémoire (ibid., fol. 275-343'). Pour l'élection de Léopold ler, cf. aussi l'»Histoire des négociations de la France dans l'Empire à l'occasion de l'élection d'un nouvel Empereur, 1657 et 1658«, »fait en 1725 décembre 31 par N. L. Le Dran, premier commis des Affaires étrangères« (AE, MD All. 40 fol. 4-77); »Mémoire de monsieur de Wrede sur l'élection d'un Roi des Romains pendant la vie de l'Empereur«, copie: AE, MD All. 41 fol. 59-88. Pour l'élection vivente Imperatore, cf. aussi l'»Examen abrégé de la valeur de la pluralité des suffrages électoraux sur l'élection d'un Roy des Romains pendant la vie de l'Empereur « (AE, MD All. 103 [1751-1753] document no 11; deuxième copie: $\mathrm{AE}, \mathrm{MD}$ Autriche 6 fol. 56-131') et plusieurs mémoires dans $\mathrm{AE}, \mathrm{MD}$ All. 104 [1750-1755]: par exemple, »Motifs des princes. Pour les faire participer aux délibérations à tenir pour décider si l'élection d'un Roy des Romains du vivant de l'Empereur est nécessaire ou non, si elle est avantageuse à l'Empire ou non?«, s.d. (fol. 11-16); »Abrégé détaillant les droits des princes à l'occasion de l'élection d'un Roy des Romains du vivant de l'Empereur «, juin 1751 (fol. 153-155); „Réflexions impartiales sur le précis du droit des princes lors de l'élection d'un Roi des Romains vivo Imperatore«, juillet 1751 (fol. 157160 '), etc. Enfin, le volume AE, MD All. 105 [1747-1753] contient un »Mémoire sur l'élection d'un Roi des Romains du vivant de l'Empereur«, s.d. (fol. 13-18') et le volume AE, MD All. 106 [1750-1753] la traduction d'un mémoire allemand sur le même problème (fol. 830). Le problème de l'élection vivente Imperatore a été étudié par NEUHAUS, Die Römische 


\section{La science du droit public allemand et le problème de l'origine de l'élection du roi des Romains et des princes électeurs}

Dans l'Empire, la science du droit public allemand naquit autour de 1600 . À ses débuts, la réception des "Six livres de la République «, de Jean Bodin, joua un rôle majeur ${ }^{7}$. Certains auteurs approuvèrent les thèses que l'auteur français avait formulées au sujet de la forme du gouvernement du Saint-Empire, alors que de nombreux juristes la rejetaient. En l'absence de père fondateur, de lieu ou d'heure de naissance, il était naturel que »les opinions divergent sur l'origine du droit public«, comme le disait l'éminent juriste Johannes Limnaeus en 16298. Toutefois, quand les premiers livres italiens et français au sujet de l'élection impériale parurent, vers 1610 , cette science du droit public allemand n'en était incontestablement qu'à son commencement. Par conséquent, les doctrines n'étaient pas encore bien forgées, en particulier dans le débat concernant l'origine des électeurs.

Malgré le nombre considérable de publications consacrées à ce sujet, l'origine des électeurs n'a pas encore pu être datée ni expliquée de manière précise par la recherche historique. En effet, le caractère rudimentaire des sources médiévales ne permettra probablement jamais de résoudre ce problème. Et le fait qu'il n'y eut pas d'acte fondateur ${ }^{9}$ joue également un rôle important. Toutefois, un consensus s'est établi concernant les caractéristiques générales de l'évolution historique. À partir du milieu du XIII' siècle, seuls sept princes de l'Empire exercèrent le droit de vote aux élections impériales, alors que ce droit avait été auparavant revendiqué et exercé par d'autres nobles. Cette restriction fut le résultat, d'un côté, d'un processus de concentration du pouvoir entre les mains de certains princes et, de l'autre, du désintéressement de certains seigneurs territoriaux à l'égard de leur participation à la décision des affaires générales de l'Empire. De 1257 à 1636, les sept princes électeurs de Mayence, de Trèves, de Cologne, de Bohême, du Palatinat, de Saxe et de Brandebourg exercèrent le droit de vote à titre exclusif ${ }^{10}$. Après la diète de Nuremberg, en 1524 , les électeurs publièrent les procès-verbaux des

Königswahl vivente imperatore. D'autres mémoires concernant l'élection impériale (1751) sont conservés aux Archives nationales, K 1371 nos 16 à 17.

${ }^{7}$ Cf. STOLleIS, Histoire du droit public, p. 255-276; Gerhard HENkEl, Untersuchungen zur Rezeption des Souveränitätsbegriffs durch die deutsche Staatstheorie in der ersten Hälfte des 17. Jahrhunderts, Marbourg 1967.

8 Cf. STOLLeIS, Histoire du droit public, p. 207.

${ }^{9}$ En 1750, un auteur français souligne cette particularité: »Le Collége des Electeurs n'est établi par aucune loi. Les Elections se faisoient anciennement avec le concours de tous les Ordres de l'Empire: mais les grands Officiers avoient toujours beaucoup plus d'autorité que les autres Etats dans les Assemblées. [...] Ils s'attribuerent peu-à-peu le droit exclusif d'Election, sans opposition de la part des autres Etats, plus occupés, particuliérement dans des tems de troubles, de leur propre sûreté que du maintien de leurs droits. [...] On voit qu'ils en étoient déja en possession par un long Usage, lorsqu'il leur fut confirmé légalement \& irrévocablement par la Bulle d'Or de l'Empereur Charles IV «, MÜLDENER, Capitulation harmonique, »Discours Preliminaire « de Besset de La Chapelle, p. IX-X.

${ }^{10}$ Seule exception: en 1273, lors de l'élection de Rodolphe Ier, la Bavière vota à la place de la Bohême. 
séances de leur collège, ce qui pouvait faciliter la connaissance de ceux-ci à l'étranger. À la veille de la publication des ouvrages de Canini et de Le Secq sur les électeurs, en 1612 et 1613, l'activité du collège électoral regagna en intensité, puisque les électeurs organisèrent trois diètes collégiales entre 1606 et 1611. Contrairement à ce que prétendait Jean Bodin, qui avait déclaré que les décisions du collège électoral n' avaient pas plus de poids que celles du collège des villes libres de l'Empire, les électeurs jouissaient de nombreuses prérogatives et prenaient seuls avec l'empereur les décisions importantes concernant la politique générale de l'Empire. Cette situation ne changea qu'à partir de 1648.

À partir du XIII' siècle, les historiens et les juristes se mirent à débattre de l'origine des électeurs. En 1271, Martinus Polonus prétendait dans sa »Chronique « que les sept »officiales Imperii« qui élisaient l'empereur avaient été instaurés à la fin de la dynastie des Othons. C'est le premier témoignage de la soi-disant fable des électeurs ${ }^{11}$, qui est l'une des sept théories principales sur l'origine du collège électoral. Cette fable connait deux versions différentes: la première attribue la création du collège au pape, la seconde à l'empereur. Les adeptes de la première version étaient particulièrement nombreux à la curie romaine, puisqu'elle permettait au pape de prétendre à un droit de confirmation de tous les changements intervenus dans la composition du collège depuis le $\mathrm{XVI}^{\mathrm{e}}$ siècle (augmentation du nombre des électeurs, admission d'électeurs protestants, etc.). C'est pourquoi les historiens ont longtemps reproché au Saint-Siège d'avoir encore défendu cette fable au XVII ${ }^{e}$ siècle, alors que plusieurs auteurs, en particulier Onofrio Panvinio, avaient déjà pu montrer qu'elle était incorrecte. Or, nos recherches sur l'image de l'Empire en France et en Italie permettent de constater que, en Italie, cette fable était approuvée non seulement à Rome mais aussi par des auteurs vénitiens et qu'elle était même connue et souvent acceptée en France. On s'aperçoit même du fait que, dans la première moitié du XVIIe siècle, des juristes allemands y souscrivirent. En 1608, Simon Schard, assesseur à la Chambre impériale, soutint par exemple cette thèse dans son traité sur l'origine des électeurs, qu'il publia à Strasbourg. En 1616, Johann Paul Windeck approuva l'interprétation papale. Au début des années 1630 , son traité sur l'origine des électeurs fut traduit en français ${ }^{12}$. Cet auteur déclarait:

Devx poincts en matiere d'estat tres importãts se peuuent reuocquer en doubte: Premieremẽt si Gregoire V. Pape de Rome, seant enuiron l'an de nostre Seigneur 1000. 1001. ou 1002. ou bien quelque autre auroit institué \& estably les Sept Hommes, ou si ceste constitution se doiue attribuer \& referer à Otton III Empereur. Ie trouue tant suiuant l'opinion de diuers Ma-

11 Dans les années 1690, un auteur français parlait explicitement de »la fable de Grégoire cinquième«, BNF, F.fr. 20134 (»Allemagne. Pièces diverses«), fol. 1 et 2-6 et fol. 7-10": deux copies d'un mémoire intitulé »Des élections des Empereurs d'Allemagne, et de l'origine des électeurs«, note, fol. 2: »par monsieur l'ab[b]é de Longuerue«, citation fol. 8.

12 Johann-Paul WINDECK, L'Origine des princes electevrs, avsquels sevls appartient l'election dv Roy des Romains [...], Lille 1632; le livre est dédié à un noble flamand, appartenant à l'un des trois ordres du pays. L'épître dédicatoire, comprenant trois pages non numérotées, est signée "Christofle Beys«; à en croire ses propres assertions, le libraire est également le traducteur de cet ouvrage. 
nuscripts, qu'autres Historiens imprimez cy apres declarez, qu'ils ont esté establis l'an 997. suiuant la sanction emanee de Gregoire V. \& publiee par le Pape Syluestre II. l'an 1000. \& ainsi l'asseurent le Pape Innocent III. au Chapitre Venerabilem, de electione [et d'autres auteurs $]^{13}$.

En 1616, Christoph Gewold chercha même à concilier les deux versions de la thèse, curiale et impériale, dans un ouvrage dédié à Paul $\mathrm{V}$ et à l'empereur Matthias. Toutefois, au cours du XVIIe siècle, la plupart des auteurs allemands adhérèrent à l'hypothèse selon laquelle le collège électoral fut instauré pendant le règne de l'empereur Frédéric II.

À côté de la théorie curiale, une deuxième explication mérite une attention particulière, puisqu'elle apparaît souvent dans les ouvrages des XVle et XVII siècles $^{14}$. Cette théorie déduit le droit de vote exclusif des princes électeurs de leur fonction d'»officiales Imperii «. Certains auteurs combinèrent cette explication avec la fable curiale. Depuis le XIII ${ }^{\mathrm{e}}$ siècle, la dénommée théorie des archi-offices (Erzämtertheorie) était propagée par Martinus Polonus et dans les »Annales Stadenses«. Schard y souscrivit également en 1608. Selon Winfried Becker, aucune de ces théories n'explique entièrement l'origine des électeurs, mais toutes peuvent contribuer à son explication, même la fable des électeurs, dont le noyau historique consisterait dans l'influence que les normes du droit canon exercèrent sur le droit public impérial en matière d'élection.

\section{L'élection du roi des Romains et la condition constitutionnelle des princes électeurs vues par les auteurs italiens au XVIe et au début du XVII' siècle}

Les intérêts que les différents États italiens avaient à l'égard de l'Allemagne divergeaient en fonction de leur statut: leur appartenance à l'Empire, pour les principautés italiennes qui faisaient partie du Saint Empire romain germanique, ou leur indépendance de l'Empire, dans le cas du Saint-Siège et dans celui de Venise, par exemple. Cependant, ces différents intérêts politiques (ainsi que les intérêts religieux à Rome et les intérêts économiques à Venise) n'impliquaient pas forcément une perception divergente de l'Allemagne en général, ni de son système politique en particulier. L'historiographie traditionnelle a prétendu que les Vénitiens se faisaient une image du Saint-Empire qui était fondamentalement différente de celle qui existait dans les États de l'Église. Or, selon nos recherches, il y avait de nombreux points de contact entre la république de Saint-Marc et la Curie, notamment en ce qui concerne la connaissance du droit public. Il faut en particulier prendre en considération le fait que, entre 1559 et $1655,10,3 \%$ des nonces apostoliques auprès de l'empereur étaient d'origine vénitienne, sans compter les autres

13 Ibid., p. 1-2.

14 Dans ce contexte, nous pouvons en revanche laisser de côté les autres théories, puisqu'elles résultent du débat entre les historiens du $\mathrm{XIX}^{\mathrm{e}}$ et du début du $\mathrm{XX}^{\mathrm{e}}$ siècle. 
envoyés du pape dans l'Empire. Beaucoup de ces nonces avaient reçu une formation en dehors des États de l'Église avant de se mettre au service de la diplomatie pontificale; une grande partie avait fait un doctorat en droit à Padoue ou à Pavie ${ }^{15}$. En outre, les copies des écrits vénitiens sur la Constitution du Saint-Empire qui sont toujours conservées dans les archives du Vatican montrent que ces textes furent lus à Rome.

L'élection impériale faisait partie des sujets privilégiés des auteurs et des lecteurs italiens. Certains États italiens (le Saint-Siège et la république de Venise) connaissaient également l'élection du chef de l'État. Depuis le XVIe siècle, ce sujet était constamment abordé dans les relations des ambassadeurs vénitiens. Souvent ces ambassadeurs comparaient l'élection de l'empereur à celle du doge. L'analyse systématique de toutes les relations des anciens ambassadeurs vénitiens auprès de l'empereur montre que pratiquement tous les auteurs acceptaient la fable des électeurs. Si la plupart des ambassadeurs adhéraient à sa version curiale (par exemple, Alvise Mocenigo en 1548), Lorenzo Contarini écrivit également en 1548 que Grégoire V ne fit que confirmer une ordonnance d'Otton III, et Federico Badoer parla en 1557 d'une décision prise en commun par le pape et l'empereur. Les auteurs vénitiens propagèrent également la théorie des archi-offices. Mais l'instauration du collège des sept électeurs était en général expliquée par la fable des électeurs. De toute évidence, les discours des ambassadeurs vénitiens étaient influencés par les interprétations curiale ou impériale.

À l'époque moderne, le Saint-Siège prêta une attention particulière aux élections impériales. Ces élections l'intéressaient même davantage que les diètes de l'Empire. Tout en prenant le titre d'»electus Romanorum Imperator « dès leur élection, depuis Maximilien Ier (1508), tous les empereurs continuèrent à demander au pape l'approbation du Saint-Siège, et en général cette confirmation fut accordée. À la différence de la politique qu'elle mena au XVIe siècle, la Curie ne chercha plus à influencer activement les élections de l'empereur au siècle suivant. Toutefois, elle ne renonça pas à réclamer son droit de confirmation pour tous les changements du droit d'élection, surtout quand la composition du collège électoral était concernée. C'est dans cette tradition pontificale qu'Innocent $\mathrm{X}$ protesta en 1648 contre l'attribution de la huitième dignité électorale au palatin du Rhin, qui était calviniste. Dans l'argumentation de la Curie, la fable des électeurs pouvait jouer un rôle important. En 1621, le nonce Carlo Carafa l'allégua notamment quand la dignité électorale palatine dut être transférée au duc de Bavière, pour éviter que cette décision ne soit prise sans l'aval du pape ${ }^{16}$.

15 Cf. Alexander KoLLER, Einige Bemerkungen zum Karriereverlauf der päpstlichen Nuntien am Kaiserhof (1559-1655), dans: Armand JAMME, Olivier PONCET (dir.), Offices et papauté (XIVe-XVII ${ }^{e}$ siècle). Charges, hommes, destins. [Actes des tables rondes, Rome, 5-6 mars 2001 et 11-13 avril 2002], Rome 2005 (Collection de l'École française de Rome, $334)$, p. 841-858, en particulier p. 850 .

16 Carafa était l'auteur d'un ouvrage imprimé en latin et d'une volumineuse description manuscrite italienne de l'Allemagne (plus de mille pages dans certaines copies), cf. BRAUN, Kaiserhof, Kaiser und Reich. 


\section{Le livre de Canini d'Anghiari sur l'élection du roi des Romains et la version française de son ouvrage publiée par Le Secq}

Il faut souligner que le premier livre en langue française sur l'élection impériale, que Le Secq publia dans la première moitié du XVIIe siècle, était la traduction d'un ouvrage italien. En 1612, la version originale fut publiée par Canini d'Anghiari à Venise en deux parties ${ }^{17}$. L'ouvrage parut à l'occasion de l'élection de l'empereur Matthias. À l'égard du collège électoral, Canini y reproduit la vieille fable des électeurs. Selon nos recherches, tout en ayant voyagé dans l'Empire, cet auteur ecclésiastique, lié tout autant aux milieux romains qu'aux milieux vénitiens, ne connaissait pas les juristes allemands de son temps.

À travers ce livre de Canini, que Le Secq publia dans sa version française à $\mathrm{Pa}$ ris en 1612 et 1613, puis pour la deuxième fois en $1633^{18}$, la fable sur l'origine des électeurs fut propagée en France. Comme l'ouvrage de Le Secq resta le seul livre imprimé français sur ce problème avant la paix de Westphalie ${ }^{19}$, il faut supposer que son influence sur le public français fut très grande, même si certains lecteurs français connaissaient certainement d'autres théories sur l'origine des électeurs, notamment celles qui étaient développées dans les ouvrages latins des juristes allemands.

\section{L'interprétation française de l'élection du roi des Romains et de l'origine du collège électoral}

Nous avons constaté que, depuis le XVIIe siècle, de nombreux ouvrages français traitaient de l'élection impériale et de son règlement par la Bulle d'or de l'empereur Charles IV. Pourtant, dans la première moitié de ce siècle, Le Secq fut le seul auteur qui écrivit sur ce sujet en langue française. Dans la deuxième moitié du XVIIc siècle, l'auteur le plus influent fut très certainement Abraham de Wicquefort, puisque son livre sur l'élection impériale fut réimprimé plusieurs fois à cette époque et même au début du XVIII ${ }^{e}$ siècle. Outre les livres imprimés, la correspondance diplomatique et la série des »Mémoires et documents « traitent comme une matière de prédilection les questions relatives non seulement à l'élection impériale en général, mais aussi à son cérémonial et aux électeurs en particulier ${ }^{20}$.

17 [CANINI D'ANGHIARI], Sommaria historia della elettione; [ID.], Compendio della Bolla di Carlo Qvarto.

18 LE SECQ, Histoire de l'election et covronnement; [ID.], Abregé de la Bvlle Doree.

19 Dans sa description de l'Allemagne, Théodore Godefroy consacre un chapitre aux électeurs, mais ne parle pas de leur origine, cf. MaletTKe, Hanke (éd.), Zur Perzeption des Deutschen Reiches, p. 91; cf. aussi le chapitre sur la Bulle d'or, ibid., p. 92-96.

20 Cf. par exemple, la lettre envoyée de Ratisbonne en 1756 par La Carrière au maréchal de Noailles; cette lettre rapporte les événements intéressants qui se sont produits à la diète de l'Empire depuis l'arrivée de Le Maire en 1754, en examinant les distinctions obtenues par 
C'est ainsi qu' on trouve, parmi ces documents, différents rapports sur le cérémonial des électeurs lors des élections impériales de $1658^{21}$ et de $1711^{22}$. Dans les

les princes électeurs depuis les préliminaires de la paix de Westphalie (AE, MD France 525 fol. 246-267).

21 Cf., par exemple, la "Relation du cérémonial observé à l'égard des ambassadeurs extraordinaires et plénipotentiaires de France à l'assemblée électorale tenue à Francfort dans laquelle le Roy de Hongrie fils de l'Empereur Ferdinand III fut esleu Empereur sous le nom de Léopold Premier. Années 1657 et 1658«, mémoire daté du 16 décembre 1740 (AE, MD All. 53 fol. 234-341). Pour le cérémonial concernant les princes électeurs en général, cf. également la note sur le »Cérémonial des ambassadeurs du Roi avec les électeurs et princes d'anciennes maisons de l'Empire «, extrait d'un mémoire remis le 26 février 1744 à l'ambassadeur du roi auprès de Charles VII (AE, MD All. 54 fol. 150-150').

22 Le volume $\mathrm{AE}, \mathrm{MD}$ All. 52 est particulièrement riche en documents concernant cette matière. Cf., par exemple, les mémoires »Sur les honneurs militaires faits à Francfort en 1711 aux électeurs et aux ambassadeurs à leur passage sur les places d'armes«, copie: AE, MD All. 52 fol. 5-55'; "Sur le cérémonial observé à Francfort en 1711 pour le fils du Roy Auguste de Pologne, prince électoral de Saxe«, copie: ibid., fol. 7-7’; »Sur les visites entre les électeurs et les ambassadeurs électoraux à la diète d'élection impériale de $1711 \ll$, copie: ibid., fol. 10-12'; »Sur la députation faite de la part du magistrat de Francfort en 1711 aux ambassadeurs électoraux, pour leur faire les présens de la ville, et sur la réception de cette députation par ces ambassadeurs«, copie: ibid., fol. 17-19; "Sur le cérémonial observé à la diette électorale tenue à Francfort en 1711 pour l'élection d'un Roi des Romains futur Empereur «, ibid., fol. 21-24 et 26bis-42'; cette copie, qui est écrite de la même main que les précédentes, porte une note en marge du titre: "Par N. L. Le Dran, chef du Dépôt des Affaires étrangères, le 31 décembre 1718 «; la note n'est pas de la même main que la copie, mais peut-être de Le Dran lui-même. Il est donc probable que toute la série de ces petits mémoires sur le cérémonial de l'élection de 1711, qui sont numérotés de 1 à 13a, soit due à Nicolas-Louis Le Dran, d'autant plus que sur la sixième pièce, Le Dran a noté: »Relatif à mon mémoire du 31 décembre 1718. N. L. Le D.«, cf. la copie de ce document intitulé: »Cérémonies observées en 1711, à l'entrée publique de l'électeur de Mayence à Francfort«, ibid., fol. 45-46; la même mention a encore été ajoutée au début du septième et du huitième mémoire (selon l'ancienne numérotation, qui ne concerne que ces documents relatifs à l'élection de 1711 et qui ne correspond pas à la numérotation actuelle de tous les documents renfermés dans ce volume): "Sur l'arrivée de l'électeur de Trève à la diette électorale de Francfort en 1711 «, copie: ibid., fol. 48; „Sur l'arrivée de l'électeur palatin à la diette électorale de Francfort en 1711 «, ibid., fol. 49 (la note ajoutée en tête ne mentionne pas le nom de Le Dran, mais elle est écrite de la même main que les notes précédentes); les documents suivants sont des copies simples sans note au début du texte: $\gg$ Sur les visites entre les ambassadeurs électoraux à la diette d'élection de 1711 «, copie: ibid., fol. 51-54'; „Sur les honneurs que les électeurs de Mayence, de Trèves et palatin se firent à la diète électoral de Francfort en 1711 dans leurs visites réciproques «, copie: ibid., fol. 58-59; »Sur le cérémonial observé en 1711 à la diette de Francfort pour le nonce du Pape«, copie: ibid., fol. 62-63'; »Sur ce qui se passa en 1711 à la diette électorale de Francfort par raport à la sortie des étrangers pour le jour de l'élection de l'Empereur «, copie: ibid., fol. 66-67'; en revanche, la pièce suivante, qui porte l'ancien numéro 13a (actuellement 12), et qui a d'ailleurs été écrite d'une autre main, est datée, dans une note ajoutée à gauche du titre, »1711 décembre 31 «; elle est intitulée: »Observations [ce mot est rayé dans l'original] sur le cérémonial employé dans le préambule et la conclusion de la capitulation de l'Empereur Charles VI«, copie: ibid., fol. 68. Mais il n'est pas impossible que l'année indiquée dans cette note renvoie seulement à l'année de la rédaction de la capitulation elle-même; en tout état de cause, la datation du 31 décembre, assez fréquente dans les mémoires rédigés par Le Dran (non seulement dans le cas des documents que nous venons 
mémoires qui furent rédigés sur cette question au dépôt des Affaires étrangères, on a très certainement utilisé d'autres sources que la seule correspondance politique. En effet, un mémoire qui est dû à Nicolas-Louis Le Dran mentionne, en marge du texte, quelques documents sur lesquels il se fonde ou auxquels il renvoie le lecteur; parmi ces sources, on trouve le »Cérémonial diplomatique « de Rousset $^{23}$, dont Le Dran a évidemment tiré une partie de ses connaissances sur le cérémonial observé en $1711^{24}$. La capitulation de l'empereur Charles VI a aussi été analysée quant aux informations qu'elle fournit sur l'élection même de cet empereur ${ }^{25}$. De plus, on a pris soin, au dépôt des archives, de dessiner un $»$ Tableau de la séance électorale pour l'élection d'un Empereur en 1711«, qui indique avec un très grand souci de précision les places des différents personnages présents à cette séance, l'emplacement des fauteuils, des chaises et des tables et figure même les fenêtres et les marches de la salle dans laquelle on s'était réuni; et de préciser que les »chaises [étaient] toutes semblables couvertes de noir pour les ambassadeurs et conseillers «, mais que les sept fauteuils dans lesquels étaient assis soit les électeurs en personne, c'est-à-dire ceux de Mayence et de Trèves, soit les premiers ambassadeurs des électeurs qui ne s'étaient pas personnellement déplacés pour assister à l'élection, au total sept personnes ${ }^{26}$, étaient »couverts de velour noir« et avaient été installés »sous un baldaquin de même étoffe«, et que les marches qui séparaient ces personnages du reste des ambassadeurs et autres personnes présentes étaient partiellement couvertes »d'un tapis noir «27.

Au siècle des Lumières, et surtout à partir de 1740, la production de livres français sur les problèmes de l'élection impériale connut un essor formidable. Cependant, pour la question de l'origine des électeurs, il semble plus intéressant d'étudier les auteurs du XVII' siècle, puisque ce fut à ce moment-là que, dans l'Empire, les connaissances dont les juristes disposaient à ce sujet devinrent de plus en plus précises. Il importe donc de savoir si les auteurs français ont suivi cette évolution dans la science du droit public. Par conséquent, après ces remarques générales, il convient d'analyser de manière plus détaillée les opinions de certains auteurs français du XVII ${ }^{\mathrm{e}}$ siècle sur l'origine du collège des électeurs.

d'énumérer, mais aussi ailleurs) semble bien être un chiffre, peut-être pour les pièces dont le jour et le mois ne sont pas très exactement connus. Le document suivant, coté de l'ancien numéro 13b (aujourd'hui 13) concerne par ailleurs la capitulation impériale dans ses parties qui ne se limitent pas au seul cérémonial.

${ }^{23}$ Il s'agit du »Supplément au corps universel diplomatique du droit des gens [...] avec le cérémonial diplomatique des cours de l'Europe«, publié par Jean Rousset de Missy (16861762) à Amsterdam en 1739; pour l'œuvre de cet auteur, cf. CIORANESCU, Bibliographie de la littérature française du dix-huitième siècle, t. III, p. 1595-1597.

24 Il cite cet ouvrage, AE, MD All. 52 fol. 22 , dans son mémoire que nous avons indiqué ci-dessus.

${ }^{25}$ Cf. l'un des documents cités ci-dessus à propos de son élection: »Observations sur le cérémonial employé dans le préambule et la conclusion de la capitulation de l'Empereur Charles VI«, copie: ibid., fol. 68.

${ }^{26}$ Les électeurs de Cologne et de Bavière se trouvant alors exclus du collège.

${ }^{27} \mathrm{Cf}$. le "Tableau de la séance électorale pour l'élection d'un Empereur en 1711 « dans le volume AE, MD All. 52 fol. 25 '-26. Ce tableau est reproduit dans ce livre. 


\section{Un traité manuscrit sur les électeurs, leur origine et leurs fonctions $(1657 / 1658)$}

Avant la publication du traité de Wicquefort consacré à l'élection impériale, en 1658 , ou en même temps que celui-ci, un manuscrit français anonyme analysa le statut des électeurs à la veille et au lendemain de la paix de Westphalie, l'origine de leur collège, les fonctions et la condition juridique des différents princes électeurs ainsi que le déroulement de l'élection impériale ${ }^{28}$. Très certainement, ce manuscrit, qui est intitulé »Des électeurs d'Alemagne « ${ }^{29}$, fut rédigé après le dixseptième anniversaire de Léopold $\mathrm{I}^{\text {er }}(8$ juin 1657) et avant son dix-huitième anniversaire ( 8 juin 1658$)^{30}$.

Cet auteur réfute explicitement la fable des électeurs. Après en avoir résumé les principaux points, il confronte les témoignages des différents historiens au sujet de l'élection impériale et fait aussi appel aux documents imprimés. Il en arrive à la conclusion que les électeurs ne furent créés que deux siècles après l'époque de Grégoire V et d'Otton III. Selon lui, le droit d'élection moderne est le résultat de la Bulle d'or de Charles IV, en ce qui concerne le nombre et les offices des princes électeurs. Étant donné que le duc de Bavière, électeur depuis 1623, n'obtint sa dignité électorale de manière définitive qu'avec la paix de Münster, la participation bavaroise dans certaines élections antérieures à la Bulle d'or est considérée comme un témoignage du fait que le règlement électoral n'avait pas encore été fixé. De toute évidence, cet auteur dispose d'une excellente connaissance des sources et dégage même les incohérences et les contradictions présentes dans les textes des auteurs allemands. Parmi les principaux auteurs ayant adhéré à la fable des électeurs, outre les cardinaux Baronius et Bellarmin, il évoque le nom de Jacques-Auguste de Thou.

Nous voyons donc que l'auteur de ce manuscrit dispose d'une connaissance approfondie de l'histoire des électeurs et que son traité réfute de manière convaincante la fameuse Kurfürstenfabel. Ses explications sont tout à fait conformes à l'état des connaissances des juristes allemands de son temps. Toutefois, le fait qu'il s'agisse d'un texte manuscrit dont nous ne connaissons qu'une seule copie peut laisser penser que le nombre de ses lecteurs fut plus limité que celui des ouvrages imprimés.

28 BNF, F.fr. 18987; il s'agit d'un petit volume in-folio du XVITe siècle de 77 folios, avec la mention suivante (fol. 1): »Ex Bibliotheca Mss. Coisliniana, olim Segueriana, quam Illust. Henricus Du Cambout, Dux de Coislin, Par Franciæ, Episcopus Metensis, \&c. Monasterio S. Germani à Pratis legavit. An. M. DCC. XXXII. [= 1732]《. À la fin, ce manuscrit contient la version française du "procès-verbal de l'élection de l'Empereur dernier mort [Ferdinand III], tiré des archives de la chancellerie de Mayence, et traduit de l'alleman[d] mot à mot « (à partir du fol. 46').

29 Sur la reliure; titre plus précis, fol. 1: „Des électeurs de l'Empire et de l'élection du Roy des Romains «.

30 En effet, ibid., fol. 29, l'auteur dit que le roi de Bohême, Léopold Ignace, »n'a que dixsept ans, estant né le $8^{\mathrm{e}}$ juin $1640 \ll$. 


\section{Wicquefort et l'origine des électeurs (1658)}

En revanche, le livre qu'Abraham de Wicquefort publia en 1658 fut très certainement l'ouvrage le plus important du XVII' siècle sur l'élection impériale ${ }^{31}$. En effet, il fut même réimprimé plusieurs fois au début du XVIII'. Il s'agit donc d'un livre incontournable si l'on veut examiner les idées qui avaient cours en France au sujet de l'origine des électeurs. On peut également noter que c'est au moment des élections impériales (en 1658 et en 1711) que ce livre fut particulièrement lu en France. Dans son traité sur l'élection de l'empereur, Wicquefort précise qu'aucune loi impériale n'avait fixé le nombre des princes électeurs avant la Bulle d'or, promulguée en 1356:

Il faut noter que la Bulle d'Or ne parle point d'aucun autre Edit, ou d'aucune autre Loy ou Constitution, qui ait réglé le nombre \& la dignité des Electeurs; mais seulement d'une ancienne \& loüable coûtume, renversant par ce moyen l'opinion de ceux qui attribuent l'institution du College Electoral à Gregoire V. \& à Otton III. Et de fait, nous avons fait voir [cidessus], que lors de l'Election de Charles IV. Auteur de la Bulle d'Or, le nombre des Electeurs n'étoit pas encore réglé ${ }^{32}$.

Le premier ouvrage publié en France au sujet de l'élection impériale au lendemain de la paix de Westphalie rompt donc avec la tradition de la théorie curiale concernant l'origine des électeurs, qui avait été propagée en France, avant 1648, par Canini et Le Secq. Wicquefort tenait même à réfuter cette théorie, comme en témoigne le titre qu'il donna au quatrième chapitre de son ouvrage. En effet, celui-ci s'intitule: »Que le College Electoral n'a pas été institué par l'Empereur Otton III. ni de son temps $\aleph^{33}$. Selon Wicquefort, la plupart des auteurs anciens et modernes pensaient cependant que la fondation du collège des électeurs remontait à Grégoire V ou à Otton III. Wicquefort retrouve notamment cette idée dans les livres des cardinaux Baronius et Bellarmin, et, toujours selon lui, la majorité des auteurs allemands et italiens optaient également pour cette datation, la principale différence consistant dans l'attribution de cette fondation tantôt à Grégoire, tantôt à Otton ${ }^{34}$. De plus, Wicquefort constate que non seulement les canonistes mais aussi les "plus exacts Historiens« soutenaient cette thèse. À cet égard, il mentionne en particulier les »Centuriateurs«, c'est-à-dire les Centuriatores Magdeburgenses $^{35}$, Sleidan (le grand historien de la Réforme au XVIe siècle) et même un éminent historien français du début du XVII' siècle: de Thou. Wicquefort évoque également le fait que la fondation du collège électoral fut parfois attribuée à

31 Nous citons ce livre d'après l'édition [Abraham DE WICQUEFORT], Discours historique de l'élection de l'Empereur [...], Rouen 1711.

32 Ibid., p. 134.

33 Ibid., p. 24.

${ }^{34}$ Cf. ibid., p. 24-25, en particulier p. 25: »la plûpart des Auteurs, tant anciens que modernes, Italiens \& Allemands, disent que les Electeurs furent instituez \& réduits au nombre de sept du temps du même Gregoire, \& de l'Empereur Otton III. mais ils disputent entr'eux, si ce Règlement fut fait par le Pape, ou bien par l'Empereur de l'autorité du Pape«.

${ }^{35}$ Il s'agit d'un groupe d'auteurs qui rédigèrent sous la direction de Matthias Flacus une histoire de l'Église en treize tomes, à Magdebourg, de 1559 à 1574. 
Otton IV, sur la base d' un document qui se révéla faux par la suite, à savoir le fragment d'une constitution de 1208, publié par Melchior Goldast. Il souligne qu'avant Martinus Polonus, qui écrivit deux cent cinquante ans après les faits, aucun auteur ne parle de l'instauration des sept électeurs vers l'an mil. Toutefois, Wicquefort a tort de s'étonner »de ce que jusques icy on ne produit point d'Acte autentique de son institution «. En effet, la recherche historique n'a pu retrouver aucun document antérieur à la Bulle d'or concernant la fondation du collège électoral, mais cette absence de document écrit s'explique par le rôle de la coutume non écrite au Moyen Âge. Wicquefort n'admet pas non plus l'idée avancée par le tchèque Dubravius, selon laquelle le collège n'aurait compris que six électeurs avant que Rodolphe Ier $n$ 'y ajoutât le roi de Bohême ${ }^{36}$. Wicquefort réfute toutes ces hypothèses en examinant chacune des élections impériales après la mort d'Otton III et en se fondant notamment sur les chroniqueurs et sur d'autres écrivains médiévaux, comme Otton de Freising, l'abbé d'Ursberg ${ }^{37}$, Ditmar de Mersebourg, Wippo, ainsi que sur des compilateurs ou des auteurs modernes tels que Melchior Goldast, Albert Krantz, etc. De plus, Wicquefort fait appel aux sources littéraires médiévales ainsi qu'aux auteurs modernes, parmi lesquels il connaît également Simon Schard. Nous voyons donc ici un auteur de langue française corriger les erreurs d'un juriste allemand, en l'occurrence Schard, celui-ci ayant pourtant été conseiller du duc Wolfgang-Guillaume de Neubourg.

Enfin, Wicquefort approuve entièrement et sans réserve l'opinion d'Onofrio Panvinio selon lequel le nombre de sept électeurs fut fixé au XIII siècle, plus précisément entre 1250 et 1280 . Toutefois, il admet comme Panvinio que ce n'est là qu'une conjecture qui n'est confirmée explicitement par aucun document. Wicquefort souligne aussi que le nombre des électeurs n'était pas encore réglé définitivement avant la publication de la Bulle d'or. Tout en adhérant à l'explication pertinente de l'origine des électeurs proposée par Panvinio, Wicquefort semble avoir tendance à sous-estimer le poids de la coutume, essentielle en droit médiéval.

Dans son huitième chapitre, consacré à des remarques de l'auteur sur la Bulle d'or, Wicquefort résume ses idées au sujet de l'origine du collège électoral: les

36 Cf. [WICQUeFoRT], Discours historique de l'élection de l'Empereur, Rouen 1711, p. 2526 (citations) et p. 27.

37 Wicquefort identifie encore cet abbé avec Conrad von Lichtenau, ibid., p. 46. En réalité, il s'agit de la chronique de Burchardus Urspergensis, ou Burchard vON URSBERG, Die Chronik des Propstes Burchard von Ursberg, éd. par Oswald Holder-Egger et Bernhard von SiMSON, Hanovre, Leipzig 21916 (Monumenta Germaniae Historica. Scriptores, 7; Scriptores rerum Germanicarum in usum scholarum, 16). L'auteur de cette chronique ne fut identifié qu'en 1771; depuis le XVIe siècle, on l'avait attribuée à Konrad von Lichtenau, prieur d'Ursberg après Burchard, cf. Norbert BACKMUND, article »Burchard von Ursberg«, dans: Kurt RuH et al. (dir.), Die deutsche Literatur des Mittelalters. Verfasserlexikon, fondé par Wolfgang STAmmLer, continué par Karl Langosch, vol. I, Berlin, New York 21978, col. 11191121 . 
sept électeurs auraient "petit à petit usurpé« le droit exclusif d'élire l'empereur ${ }^{38}$, en excluant d'autres princes, en profitant de l'extinction de plusieurs familles princières, de la réunion de certaines principautés jouissant du droit d'élection ou du détachement de l'Empire de certaines provinces, comme l'Italie. De cette manière, les électeurs auraient acquis leur droit exclusif à l'élection »par une coûtume insensiblement introduite, particulierement pendant les schismes, qui commencerent à ruiner l'Empire sous \& après le Régne de Frideric II. en sorte que cette coûtume n'a passé en force de Loy fondamentale, que par la publication de la Bulle d'Or «39.

Le livre de Wicquefort reflète donc parfaitement l'état des connaissances sur l'origine des électeurs tel qu'il se présentait au milieu du XVII e siècle. Or, il faut se demander si les conclusions de Wicquefort furent unanimement reprises dans les ouvrages français, à partir de la deuxième moitié du XVIIe siècle. Pour dresser un bilan nuancé des opinions avancées par les auteurs français, il est nécessaire de prendre en considération aussi bien des livres qui poursuivaient de toute évidence des objectifs de propagande très précis que des ouvrages historiques plus ssérieux<, tout en sachant qu'il n'est pas toujours possible de distinguer clairement ces deux catégories de publications. Nous commencerons avec le »Tableau historique« que Nouvelon publia environ dix ans après le livre de Wicquefort, en 1669.

\section{L'instauration du collège électoral selon Nouvelon (1669)}

Dans son »Tableau historique« de 1669, Nouvelon se fait l'écho de la théorie de la translatio Imperii. Or, selon lui, le projet de la translation de l'Empire d'Occident en Allemagne, d'ordinaire attribué par les auteurs français aux Othons, qui auraient transféré l'Empire de France en Germanie, remonte à Charlemagne, obligé de s'installer outre-Rhin à cause de l'instabilité politique et militaire de cette région, où il entreprit de grands travaux d'infrastructure ${ }^{40}$. L'empereur s'installa à Aix-la-Chapelle, qui, comme le souligne Nouvelon, faisait bien partie de la Gaule et non des pays d'outre-Rhin. Ainsi, la translation de l'Empire aux Allemands ne fut achevée que par Otton III, après que les Italiens eurent de leur côté tenté de le récupérer ${ }^{41}$. Nouvelon considère que ce sont ces tentatives italiennes qui impulsèrent les efforts redoublés d'Otton III pour conserver durablement l'Imperium en Allemagne. À cette époque, le roi de France, Hugues Capet, était trop accaparé par l'établissement de son propre pouvoir dans le royaume, peu de temps après son avènement, pour s'opposer à un tel projet; mais, selon la généalogie retenue

38 Cf. [WICQUEFORT], Discours historique de l'élection de l'Empereur, Rouen 1711, notamment p. 42-44, 54, 61-62, 65, 69 et 135 .

39 Ibid., p. 135-136.

40 Nouvelon, Tableau, p. 29. Sur ce projet de la translation de l'Empire d'Occident en Allemagne, cf. aussi ibid., p. 32-35.

41 Cette datation de la translation par Nouvelon coïncide bien avec celle qui est indiquée par les autres auteurs français qui admettent la théorie de la translatio Imperii. 
par Nouvelon, Hugues Capet et les Othons descendaient tous de Charlemagne, en lignée féminine, de sorte que Nouvelon prétend qu'»on pouvoit encore dire que ny les fleurs de lis Françoises, ny l'aigle Romaine, n'estoient encore separées de la posterité de Pepin « 42 . Avant l'an mil, les histoires de France et d'Allemagne auraient donc toujours en commun une certaine tradition carolingienne. Nouvelon retient le fait que l'Empire passa définitivement aux Allemands par un accord conclu entre Otton III et Grégoire V:

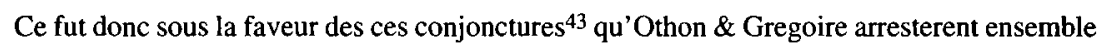
d'un commun accord, que pour l'avenir le seul pouvoir de disposer de l'aigle Romaine, \& de créer les Cesars appartiendroit à l'Allemagne; \& qu'il ne seroit plus permis aux Papes de declarer ny reconnoistre pour Empereur qui que ce fust, si premierement l'assemblée des Grands de cette Nation ne l'avoit solemnellement choisi pour une si haute dignité; Et s'il n'avoit receu le jour en Allemagne, \& non ailleurs ${ }^{44}$.

Nouvelon tranche donc très nettement la question de savoir si un étranger pouvait être élu empereur, un problème qui fut pourtant très controversé en France comme dans l'Empire. Pour Nouvelon, la création même du collège électoral était avant tout un moyen inventé par les Allemands afin de se réserver la dignité impériale et non le résultat d'une concentration du droit de vote entre les mains de certains princes allemands - au détriment d'autres états qui pouvaient y prétendre. Nouvelon n'adhère pas à la théorie de l'institution des sept électeurs de l'Empire par Grégoire V, chère au Saint-Siège, mais il la connaît bien:

Quelques Historiens ont estimé que ce fut en ce temps-là que le Septem-Virat des Electeurs de l'Empire fut estably, \& quelques autres soûtiennent que cet establissement ne se fit qu'aprés plus d'un siecle, c'est à dire, en un temps que la France devenuë aussi puissante que jamais par sa concorde domestique, eust peu sans beaucoup de peine, $\&$ avec toute sorte de justice, empescher une institution qui pour obliger la seule Allemagne, desobligeoient tout le reste de la Chrestienté; puisqu'on ordonnoit expressément à ces Electeurs de choisir un Empereur qui fust Allemand de nation, afin que ce choix le rendist entierement attaché à l'Allemagne, tant par naissance que par intérest ${ }^{45}$.

Nouvelon réserve donc à la France un droit d'intervention contre l'institution du collège électoral qui, comme elle regarde la dignité impériale, ne peut pas, selon lui, être décidée seulement par les Allemands. Or, la nationalité de l'empereur, ou de celui qui pouvait se porter candidat à l'Empire, n'était point décidée par les lois fondamentales impériales avec autant de clarté que Nouvelon le prétend. Il ne pouvait être question d'une exclusion formelle de tous les étrangers, même si ceux qui tentèrent d'être candidat ou y pensèrent, tel François I ${ }^{e r}$ après la mort de Maximilien Ier, durent affronter ou envisager de nombreuses difficultés à cause de leur origine ${ }^{46}$. À part cela, le nombre des électeurs ne fut fixé que par la Bulle d'or

42 Cf. Nouvelon, Tableau, p. 35-36, 53-54 et citation p. 52.

43 L'avènement de Hugues Capet en France et ses efforts pour y assurer son propre pouvoir.

44 Nouvelon, Tableau, p. 54.

45 Ibid., p. 54-55.

46 Cf. BABEL, Deutschland und Frankreich im Zeichen der habsburgischen Universalmonarchie, en particulier p. 161-165. 
de Charles IV, en 1356. Si la France permit à l'Allemagne d'instaurer ce collège électoral, ce ne fut, selon Nouvelon, que par générosité, car sa puissance lui aurait permis de s'y opposer. Même la participation au collège électoral des trois électeurs ecclésiastiques, c'est-à-dire des archevêques de Mayence, de Cologne et de Trèves, était pourtant perçue comme une espèce d'usurpation d'anciennes terres gauloises par l'Allemagne, comme il résulte des observations de Nouvelon sur la réaction que la France réserva à cette institution des sept électeurs:

Cependant la France eut assez de bonté pour souffrir que par la hardiesse de cette disposition, la dignité Imperiale demeurast eternellement interdite aux François, qui l'avoient acquise les premiers, \& que mesme les trois principaux Prelats de l'Austrasie, estant mis au nombre des Electeurs de l'Empire d'Allemagne, demeurassent pour l'avenir détachez du corps de la France; auquel l'Austrasie avoit appartenu de tout temps; puis qu'elle avoit obey non seulement à Pepin \& à Charlemagne, mais encore à Charles le Simple; ainsi que le traité de Bonne fait assez connoistre ${ }^{47}$.

La France a-t-elle jamais formellement renoncé au droit de proposer un de ses ressortissants à une élection impériale? L'Allemagne a-t-elle jamais demandé à la France une telle renonciation? Ces questions sont à trancher par la négative. Supposons donc que Nouvelon ne veuille pas parler d'une simple candidature individuelle, mais d'un véritable transfert de la dignité impériale en France; même dans ce cas de figure, il n'y a ni obligation ni renonciation. En outre, ce n'est pas par l'acquisition du titre d'électeur du Saint-Empire que les trois archevêques du Rhin ont intégré l'Allemagne; telle est, pourtant, l'explication que tente Nouvelon ${ }^{48}$. Ces remarques au sujet de l'origine du collège électoral représentent plus une construction historique qu'une reconstruction des réalités. Comme la datation de l'institution du collège électoral qu'il admet est floue, et même incorrecte, Nouvelon construit un enchaînement logique entre la création du collège et l'appartenance des trois archevêchés du Rhin à l'Allemagne qui n'est pas conforme à la véritable chronologie; d'abord états de l'Empire, ces archevêques devinrent électeurs du Saint-Empire, et non l'inverse ${ }^{49}$. La question des frontières fut évidemment cruciale en 1669, deux ans après qu'Antoine Aubéry eut publié ses »ivstes pretentions dv Roy svr l'Empire «s0.

47 Nouvelon, Tableau, p. 55. Le traité de Bonn fut conclu le 7 novembre 921 par Charles III, rex Francorum occidentalium, et par Henri Ier, rex Francorum orientalium. Cf., à propos de ce traité mentionné par Nouvelon, K[arl] F[erdinand] WERNER, article »Bonn, Vertrag von«, dans: Lexikon des Mittelalters, t. II (1981-1983, $\left.{ }^{2} 1999\right)$, col. 428-429.

48 Nouvelon, Tableau, p. 55-56.

49 Par ailleurs, Nouvelon lui-même, toujours attaché aux frontières carolingiennes, ne va pas jusqu'à expliquer l'indépendance des Pays-Bas à l'égard de la France par la création des électorats: »la cause de cette separation se trouve principalement parmy les desordres dont la France fut agitée sous les Regnes de Charles le Simple \& de Loüis d'Outremer son fils" (ibid., p. 57-59, citation p. 57).

50 Cf. [Antoine] AUBÉRY, Des ivstes pretentions dv Roy svr l'Empire [...], Paris 1667. Pour cet auteur, cf. aussi Winfried DOTZAUER, Der publizistische Kampf zwischen Frankreich und Deutschland in der Zeit Ludwigs XIV. Der Publizist Antoine Aubery und seine Gegner (1667-1669). »Des iustes prétentions du Roi sur l'Empire«, dans: Zeitschrift für die Geschichte des Oberrheins 122 = nouv. sér. 83 (1974), p. 99-123. 
Bien que n'adhérant pas à la fable de l'origine des sept électeurs soutenue par la curie romaine, Nouvelon invente ou reprend à son compte une autre fable, qui faisait des électeurs des créatures instituées non pas par la grâce du pape, mais par la grâce du roi de France:

Que si le titre de Prince du S. Empire, qui est demeuré à ces Electeurs, en a détaché quelquesuns de l'affection qu'ils devoient avoir pour les Roys Tres-Chrestiens, il est certain que de temps en temps quelques autres d'entr'eux se sont montrez assez raisonnables pour considerer que s'ils ont receu des Allemans la qualité d'Electeurs, ils avoient auparavant receu des François la qualité de Prelats; \& qu'enfin l'Allemagne ne peut passer que pour leur pays adoptif; au lieu que la France est leur naturelle Patrie.

Selon Nouvelon, la condition des sept électeurs correspond à celle des empereurs, avec des retombées bénéfiques sur l'économie de leurs territoires et sur toute l'Allemagne ${ }^{51}$. En réalité, les trois électorats ecclésiastiques du Rhin étaient des États territoriaux fort modestes au milieu du XVIIe siècle, et, abstraction faite de leur participation au collège électoral et aux élections de rois des Romains et d'empereurs, leur puissance devint inférieure à celle de certaines principautés séculières non électorales dès la première moitié du siècle, comme le rappelle à juste titre Fritz Dickmann ${ }^{52}$. En ce qui concerne la condition juridique des électorats en général, on peut en conclure qu'ils sortirent plus affaiblis que renforcés du congrès de Westphalie, puisque les autres états de l'Empire réussirent à empiéter sur des prérogatives dont ils avaient avant le monopole ${ }^{53}$.

La seule chose que l'on puisse retenir d'authentique dans cette narration fabuleuse des origines des électeurs, c'est le caractère bénéfique que le règlement institutionnel de l'élection impériale eut sur la stabilité politique du pays. Cependant, Nouvelon exagère certainement ses conséquences économiques, et surtout la mission quasi civilisatrice des trois archevêques austrasiens, l'histoire étant ici de toute évidence mise au profit de la propagande politique. L'objectif de cette propagande était de démontrer la supériorité de la royauté française sur la dignité impériale. Dans cette perspective, Nouvelon nie toute tentative française d'accéder à l'Empire et décrit le Roi Très Chrétien comme le véritable successeur de Charlemagne ${ }^{54}$. Les réserves formulées par cet auteur sur la politique des empereurs médiévaux furent aussi discutées, sous des auspices différents, par l'historiographie allemande du XIX ${ }^{e}$ siècle, qui s'interrogea sur la question de savoir si l'attachement à la dignité impériale et la présence impériale qu'elle nécessita en Italie constituèrent un obstacle à la formation d'une nation allemande ${ }^{55}$. Il paraît

51 Cf. Nouvelon, Tableau, p. 56-57, citation p. 56.

52 DickmanN, Der Westfälische Frieden, p. 26.

53 Au sujet des règlements modifiant, dans une certaine mesure, la position des électeurs en Westphalie au profit des autres états de l'Empire, voir ibid., en particulier p. 325-332.

54 Cf. Nouvelon, Tableau, p. 64-65.

$55 \mathrm{Au}$ sujet de ce débat opposant Heinrich von Sybel à Julius Ficker, cf. Friedrich ScHNEIDER (éd.), Universalstaat oder Nationalstaat. Macht und Ende des Ersten deutschen Reiches. Die Streitschriften von Heinrich v. Sybel und Julius Ficker zur deutschen Kaiserpolitik des Mittelalters, Innsbruck 21943; Volker DOTTERWEICH, Heinrich von Sybel. Geschichtswissen- 
tout à fait légitime et même indispensable de réfléchir sur le bien-fondé de cette politique, à condition que l'on cherche à l'interpréter dans l'arrière-fond de la pensée politique du Moyen Âge même. Or, la candidature de François Ier, à l'aube des Temps modernes, montre bien que les rois de France n'ont pas toujours été complètement insensibles à toute tentation de se faire élire empereur, et l'on sait bien que, même au XVII' siècle, Louis XIV ne s'en abstint qu'après de mûres réflexions du côté français. Or, Nouvelon explique cette candidature de François Ier uniquement par la nécessité que le roi de France ressentit d'empêcher l'accession de Charles Quint au trône impérial.

Mais le souci de Nouvelon était de donner une vision idéalisée de la royauté française, qui en faisait, sinon l'héritière du titre d'empereur, du moins celle »de la gloire \& de la puissance de Charlemagne «, le trône des rois de France devenant, notamment par le soutien qu'ils apportèrent aux croisades, »un des principaux boulevards de la Chrestienté «56. D'après Nouvelon, les relations entre les Français et les Allemands étaient marquées par une grande sympathie réciproque au moment où Charles Quint prit le pouvoir dans l'Empire. C'est donc l'empereur, issu de la maison d'Autriche, qui était présenté comme le véritable adversaire de la France, alors que le peuple et les princes allemands étaient considérés comme ses amis. Au sujet de l'élection de l'empereur, nous avons constaté que Nouvelon connaissait encore bien la fable qui attribuait l'instauration du collège des sept princes électeurs à Otton III ou à Grégoire V. Celle-ci était donc toujours présente à l'esprit des auteurs français. Tout en réfutant l'hypothèse de la création du collège par l'autorité papale, Nouvelon formule une autre théorie, qui n'est pas plus correcte, puisqu'elle déduit le pouvoir des électeurs de l'autorité du roi de France. Passons à présent à un autre auteur français qui écrivit pendant la guerre de Hollande, en 1675.

\section{Les électeurs vus par Bruneau en 1675}

D'après Antoine Bruneau, les électeurs étaient les plus éminents membres du Saint-Empire. Avant de décrire chacun des huit électorats qui existaient à son époque, Bruneau fait en effet quelques remarques sur la dignité électorale en général, sur l'origine des électeurs et sur les transformations que leur ordre a subies au XVII siècle, remarques qui, malgré leur brièveté, font bien voir de quelle manière Bruneau conçoit le statut constitutionnel des électeurs. Ces derniers sont, pour lui, ceux qui mettent la dernière main aux décisions de la diète impériale et dans tous les cas où il s'agit de prendre des décisions regardant tout l'Empire, et ils sont aussi le fondement même de la puissance impériale. Il commence son »Estat des Electeurs en general« de la façon suivante:

schaft in politischer Absicht (1817-1861), Göttingen 1978 (Schriftenreihe der Historischen Kommission bei der Bayerischen Akademie der Wissenschaften, 16).

56 Cf. Nouvelon, Tableau, p. 65-66 (citations) et p. 77-82. 
Soit dans les assemblées des Estats, soit dans les autres affaires de l'Empire, les Electeurs ont toûjours esté envisagez des autres membres comme ceux qui y donnent la derniere fin: leurs preéminences \& leurs puissances les font respecter des autres comme l'écueil ordinaire de la Majesté Imperiale.

Dans cette perspective, son interprétation du traité de Münster est pourtant trop optimiste à l'égard des électeurs, quand il prétend que ce traité de paix a encore affermi leur position, en augmentant même leur souveraineté et en les rendant indépendants:

Le Traité de Munster, en portant la souveraineté des Electeurs jusques au plus haut point où ils la pouvoient souhaiter, semble en mesme temps avoir donné lieu à la suite des affaires que nous voyons aujourd'huy, puis que les Electeurs aussi-bien que les autres Princes ont crû que c'estoit une loy fondamentale qui ne pouvoit estre aneantie, que par le bouleversement de la grandeur \& de la liberté de l'Empire. Ils se sont imaginez que leur indépendance qui sembloit si solidement affermi, ne pouvoit recevoir aucune atteinte ${ }^{57}$.

En réalité, il ne fut en aucune manière question, dans les traités de Westphalie, d'étendre les droits et la prééminence des électeurs. On a au contraire pu soutenir que leur position avait plus souffert que celle de l'empereur, dans ces traités, puisque les états d'Empire se sont réservé un droit de codécision dans des affaires que les électeurs n'avaient l'habitude de régler qu'avec l'empereur ${ }^{58}$. Or, cet aspect des divergences d'intérêt existant entre les différents ordres de l'Empire est négligé par Bruneau, qui réduit la politique intérieure allemande à un conflit entre les états et l'empereur. Si les électeurs et d'autres états d'Empire ne s'opposaient pas à l'empereur, c'est qu'ils agissaient, selon Bruneau, contre leurs véritables intérêts, connaissant mal leur propre situation. C'est pourquoi la condition des électeurs, originairement tenus pour les $\gg$ Dieux tutelaires de la liberté Germanique « 59 , a beaucoup souffert après 1648 , d'après Bruneau, et notamment durant la guerre qui était en cours, et dans laquelle de nombreux princes et même la diète s'étaient rangés du côté de l'empereur ${ }^{60}$. Toujours selon Bruneau, les électeurs auraient, par leur comportement dans cette guerre, mis en danger leur propre prééminence et, par là même, la liberté de tous les états de l'Empire. Bruneau pense évidemment au soutien que les états apportèrent à l'empereur. Au fond, il reproche à certains états, et en premier lieu aux électeurs, d'avoir fait confiance à la maison d'Autriche après 1648, alors que Bruneau tient cette dernière pour l'adversaire de leurs propres intérêts ${ }^{61}$.

${ }^{57}$ Cf. Bruneau, Estat, p. 71-74, citations p. 71-72; cf. aussi ibid., p. 25-26, où l'auteur s'explique de la même façon sur les traités de Westphalie. Bruneau juge aussi que, après 1648 , la »condition [des états d'Empire] estoit plûtost d'Alliez inégaux en forces, que de vassaux de l'Empereur «, ibid., p. 27.

58 MALETTKE souligne que Bruneau surestimait la position des électeurs après la paix de Westphalie, cf. ID., Altes Reich und Reichsverfassung in französischen Traktaten, p. 221258, ici p. 238.

59 BRUNEAU, Estat, p. 71.

60 Pour la situation politique internationale à ce moment-là, cf. MALETTKE, Les relations entre la France et le Saint-Empire, p. 297-365.

${ }^{61}$ Cf. BRuneau, Estat, p. 71-72. 
Ces remarques montrent que la Constitution de l'Empire n'était pas encore étudiée vers $1675 \mathrm{~d}$ 'une manière >scientifique< par une très grande partie des auteurs français et de langue française comme ce sera le cas au XVIIIe siècle; en effet, elle ne les intéressait souvent qu'en tant qu'instrument et source d'arguments dans le débat sur l'actualité politique ${ }^{62}$. L'objectif de cette instrumentalisation du débat constitutionnel était d'assurer à la France la bienveillance et, le cas échéant, la neutralité, voire le soutien politique (ou militaire) des états de l'Empire.

Cela n'empêche pas un auteur comme Bruneau de percevoir correctement de nombreux aspects de cette Constitution. À titre d'exemple, on peut citer ses observations sur l'origine des électeurs; quoique très brèves, ses remarques résument correctement les certitudes que l'on avait sur l'origine et le nombre des électeurs, tandis que d'autres auteurs, à l'instar des Italiens, avaient parfois encore tendance à admettre l'instauration des sept électeurs avant même l'an mil ou peu après; Bruneau s'en tient en revanche à ce qui est irréfutable: "L'origine de l'établissement le plus certain des Electeurs se rapporte à la Bulle d'or que les Allemands regardent comme la loy fondamentale de leur Empire, dont l'Empereur Charles IV. fut l'auteur l'an 1356 . \& reduisit les Electeurs au nombre de sept $\aleph^{63}$.

Le fait que Bruneau ajoute les mots »le plus certain« montre qu'il savait bien que les publicistes avaient formulé différentes hypothèses sur les origines du collège électoral ${ }^{64}$. Pourtant, contrairement à d'autres auteurs, Bruneau n'admettait aucune possibilité d'abroger certaines stipulations de la Bulle d'or, même si cette abrogation se faisait avec le consentement des états de l'Empire, comme ce fut le cas au congrès de Westphalie quand on entérina le transfert de la dignité électorale palatine à la Bavière, et à l'égard du nombre des électeurs quand on ajouta, au même moment, un huitième électorat pour le palatin aux sept dignités électorales qui existaient auparavant. En effet, Bruneau remarque à ce propos que la Bulle d'or ayant institué sept électorats, »le Traité de Munster en a crée [sic] vn huitiéme, \& ce n'est pas dans cet article seul que la Bulle d'or se trouve violée « 65 . Après de mûres réflexions, les publicistes d'Allemagne étaient arrivés pour autant à la conclusion qu'une modification du nombre des électeurs était bien possible

62 Du moins en ce qui concerne les ouvrages imprimés; en revanche, les manuscrits, par exemple ceux des Dupuy et des Godefroy, représentent des travaux d'érudits plutôt désintéressés.

63 BRUNEAU, Estat, p. 72. Par la suite, Bruneau rapporte encore quelques principes concernant l'élection impériale et les électorats sans se référer explicitement à la Bulle d'or, comme, par exemple, le problème des électeurs séculiers mineurs et la négation du droit de vote des chapitres des électorats ecclésiastiques vacants, ibid., p. 74.

$64 \mathrm{Cf}$. la citation ci-dessus alléguée; d'ailleurs, Bruneau est bien au courant d'autres litiges, comme, par exemple, du différend entre les électeurs bavarois et palatins concernant la question de savoir si le vicariat de l'Empire était transféré avec la dignité électorale palatine au duc de Bavière, ou si la maison palatine pouvait la conserver comme lui étant propre, même après avoir été reléguée en huitième et dernière position au collège électoral, cf. ibid., p. 73-74. 65 Ibid., p. 72-73. 
avec le consentement des états, et qu'elle ne constituait donc pas une violation de cette loi fondamentale ${ }^{66}$.

Enfin, on peut noter que Bruneau ne retient pas toutes les prétentions du Saint-Siège à l'égard de l'élection impériale, précisant que la confirmation papale n'était pas nécessaire pour qu'un archevêque-électeur y participât ${ }^{67}$. Or, le Saint-Siège réclamait un droit de confirmation de l'élection impériale, en prétendant que l'autorité du pape était à l'origine de l'élection de l'empereur et du pouvoir des princes électeurs. Nous pouvons donc constater que Bruneau n'admet ni la fable curiale concernant l'origine des électeurs ni ses conséquences juridiques défendues par le Saint-Siège. Comme Bruneau le dit très clairement, les sept électeurs furent institués par la Bulle d'or au XIVe siècle. Toutefois, en se limitant à cette loi fondamentale, il néglige le fait que, à partir du siècle précédent, les sept électeurs commencèrent à exercer exclusivement le droit de vote aux élections impériales. Bruneau est conscient du fait que sa datation de l'origine du collège électoral n'était pas unanimement acceptée. Le tableau positif qu'il brosse des prérogatives des électeurs s'explique certainement par le fait que la France courtisait les princes électeurs pour conserver leur bienveillance et pour les détacher du camp impérial pendant la guerre de Hollande. Quatre ans après Bruneau, Maimbourg publia un ouvrage historique qui compte parmi les principales publications françaises sur l'Empire de la deuxième moitié du XVII siècle.

\section{L'origine de l'élection des empereurs, des électeurs et du collège électoral selon Maimbourg (1679)}

Dans le livre II de son »Histoire de la décadence de l'Empire«, Maimbourg se livre à une dissertation sur l'origine des élections impériales, des électeurs et du collège électoral, qui, comme cet auteur le sait, ne furent instaurés à la fin du $\mathrm{X}^{\mathrm{e}}$ siècle ni par le pape Grégoire V ni par l'empereur Otton $\mathrm{III}^{68}$. Par conséquent, Maimbourg met au conditionnel cette fable que nous venons de résumer, et à laquelle il n'ajoutait pas foi ${ }^{69}$. Il faut d'abord noter que Maimbourg savait parfaitement qu'il s'agissait d'un problème sur lequel les discussions avaient été âpres, en particulier au XVIe siècle, au-delà même des clivages nationaux ou confessionnels. Au lieu d'adhérer sans réserve à l'une ou à l'autre des positions, il souligne

66 Sur les avis que défendaient les députés des états de l'Empire au sujet de l'instauration d'un huitième électorat, cf. DickmanN, Der Westfälische Frieden, p. 378-379 et p. 399-400. ${ }^{67}$ BRUNEAU, Estat, p. 74.

68 Maimbourg, Histoire de la décadence de l'Empire, livre II: »Dissertation historique sur l'origine de l'élection des Empereurs \& du College Electoral qui ne vient ni de Grégoire ni d'Othon«, p. 104-119 (titre d'après le »Sommaire« au début de l'ouvrage, non paginé).

${ }^{69} \mathrm{Cf}$. ibid., p. 104: »[Grégoire V] celébra un Concile à Rome, où plusieurs se sont voulu persuader que, pour favoriser sa Nation, il avoit institué le College des sept Electeurs, tous Princes Allemans, qui auroient desormais uniquement le droit d'élire les Empereurs«. 
que l'origine du collège électoral est l'un des points les plus obscurs de l'histoire constitutionnelle du Saint-Empire au Moyen Âge ${ }^{70}$; après l'examen des faits établis par les historiens et les juristes jusqu' au XVIIe siècle, il penche pour la thèse selon laquelle le collège électoral aurait été créé par la Bulle d'or de Charles IV, même si ses origines remonteraient au XIII' siècle. En revanche, il exclut toute hypothèse d'une création antérieure à cette époque. Dans l'ensemble, ses conclusions correspondent aux connaissances actuelles sur la datation de l'origine des électeurs. Dans cette digression, Maimbourg retrace les différentes étapes qui marquèrent la naissance de l'élection impériale et la création du collège électoral; il en résulte clairement que Maimbourg considère l'instauration de ce collège non comme un acte unique (tel que Baronius l'avait conçu), mais comme un processus qui aboutit progressivement à l'institutionnalisation définitive du corps des sept électeurs par la Bulle d'or de Charles IV.

Maimbourg a le mérite d'alléguer en marge du texte les livres sur lesquels il fonde son récit; dans le corps de son exposé, il se livre en outre à la critique des principaux auteurs sur lesquels il s'appuie. Parmi les sources et les autorités auxquelles il eut recours, Abraham de Wicquefort est le seul auteur du XVIre siècle à avoir écrit en français. Maimbourg le cite à deux reprises: tout d'abord au sujet des changements intervenus dans la composition des assemblées convoquées pour les élections impériales, avec notamment l'admission des députés des villes, puis au sujet de la Bulle d'or de Charles IV. En outre, il a consulté certains auteurs médiévaux qui ont écrit sur l'histoire des différentes élections impériales, tels que Otton de Freising, Albert de Staden, et Widukind de Corvey ${ }^{71}$. Néanmoins, il n'ajoute pas foi à tous ces auteurs et critique en particulier Mathieu Paris. De plus, Maimbourg renvoie aux actes des différents conciles et des synodes médiévaux, ainsi qu'au décret de Gratien. Enfin, il connaît les épîtres et les décrets vrais ou supposés des papes concernant les élections de l'empereur ${ }^{72}$.

Parmi les auteurs italiens, Maimbourg a consulté les cardinaux Bellarmin et Baronius, qu'il s'efforce de réfuter point par point; il a également lu les vies des papes écrites par Platina. En ce qui concerne les auteurs allemands qui ont vécu et écrit après la promulgation de la Bulle d'or, on peut notamment relever les noms

70 Cf. ibid., p. 104-105: "Il faut avoûër que c'est icy un des points de l'Histoire le plus obscur, \& le moins connu, \& sur lequel on a écrit avec plus de chaleur, plus de diversité de sentimens, \& plus de préoccupation, non seulement du costé des Protestans, mais aussi de celuy des Catholiques qui ne s'accordent pas entre eux: de-sorte qu'après avoir leû ce grand nombre de livres $\&$ de traitez qui ont paru sur ce sujet dans le dernier siécle, on se trouve à peu prés aussi embarassé qu'auparavant«.

71 Widukind de Corvey (né vers 925, mort après 973), auteur des »Annales Witichindi Monachi Corbeiensis« ou »Rerum gestarum Saxonicarum libri tres«. Ses »Annales « sont également citées dans un mémoire conservé parmi les documents diplomatiques français et rédigé en français après 1740, par un certain Wrede, au sujet de l'élection vivente Imperatore, copie: AE, MD All. 41 fol. 59-88, en particulier fol. 59'-60.

72 Cf. Maimbourg, Histoire de la décadence de l'Empire, p. 105-119. 
de Conring ${ }^{73}$, Windeck ${ }^{74}$, Krantz ${ }^{75}$, Naucler ${ }^{76}$ et Gretser ${ }^{77}$. Dans son ouvrage, Maimbourg ne renvoie que rarement à la littérature allemande comtemporaine, et il ne discute que ponctuellement des thèses qui étaient formulées. Même s'il était conscient du fait que les Allemands discutaient vivement du problème que posait l'origine du collège électoral, il n'est donc pas certain que Maimbourg ait eu une connaissance approfondie des principaux auteurs en particulier. En revanche, il est certain qu'il connaissait très bien Baronius, tout en ne souscrivant pas aux conclusions de cet auteur. Pour ce qui est de la connaissance des auteurs allemands, l'ouvrage de Maimbourg est typique de la littérature française des XVII et XVIII' siècles portant sur l'histoire et le droit public de l'Allemagne médiévale, dans la mesure où les auteurs allemands qui écrivaient en latin au Moyen Âge sont cités plus fréquemment que les auteurs modernes et parce que, parmi ces derniers, ceux qui écrivaient en latin sont mieux connus que leurs compatriotes écrivant dans leur langue maternelle.

D'après Maimbourg, l'Empire prit un caractère électif dès l'extinction de la lignée carolingienne. La première forme d'élection fut marquée par le concours général tant des princes ecclésiastiques que des princes séculiers et des villes ${ }^{78}$. Il n'adhère donc pas à l'opinion de certains auteurs qui ont relativisé ce caractère électif, en le restreignant dans un premier temps aux changements de dynastie. En revanche, Maimbourg insiste sur la césure qui sépare l'Empire carolingien et celui des Othons et tient à souligner que ce premier changement de dynastie entraina

${ }^{73}$ Cf. ibid., p. 105-107, 109-110, 112, 114-115, 117-119; voir également Hermann CoNRING, De Germanorvm Imperio Romano liber vnvs. Accessit Francisci Gvicciardini Discursus de origine secularis potestatis in Romanâ Ecclesiâ, Helmstedt 1644; ouvrage dédié au duc Auguste de Brunswick-Lunebourg. Comme d'autres juristes protestants qui n'admettaient pas la théorie curiale, Hermann Conring prétendit en 1644 que le droit de participer à l'élection avait été conféré aux électeurs par les autres princes allemands.

74 Cf. Maimbourg, Histoire de la décadence de l'Empire, p. 106-107, 113; voir Johann Paul WINDECK, Commentarivs de principvm electorvm, quibvs Regis Romanorvm electio commendata est origine [...], Cologne 1616. Windeck était un adepte de la théorie curiale.

${ }^{75}$ Cf. Maimbourg, Histoire de la décadence de l'Empire, p. 113. L'Histoire de Saxe d'Albert Krantz (1463-1517) avait été examinée par la congrégation de l'Index, à Rome, en 1582 et en 1606, cf. BRAUN, Ein italienischer Blick, p. 92, n. 94. Il est.donc surprenant de voir un auteur ecclésiastique comme Maimbourg recourir à cet ouvrage.

76 Cf. Maimbourg, Histoire de la décadence de l'Empire, p. 113, 119; la »chronique« du juriste Johann Nauclerus du XVe siècle fut également utilisée par Canini et Le Secq, cf. BRAUN, Ein italienischer Blick, p. 81.

${ }^{77}$ Cf. Maimbourg, Histoire de la décadence de l'Empire, p. 113. Maimbourg se réfère probablement à Jakob Gretser S.J. (1562-1625), théologien, historien, professeur à Ingolstadt et auteur, entre autres, d'un livre concernant les rapports entre les empereurs et les papes: Jacob GRETSER, Commentariolus de Imperatorum, Regum ac principum christianorum in Sedem Apostolicam munificentia, Ingolstadii 1610. Cf. Leonhard LENK, article »Gretser (Gretscher), Jakob«, dans: Neue deutsche Biographie, vol. III (1966), p. 51-53.

78 Cf. Maimbourg, Histoire de la décadence de l'Empire, p. 105. Maimbourg renvoie, en marge de ce paragraphe, à Widukind et à Luitprand. Luitprand ou Liutprand de Crémone (vers 920-972) était historien; il fut évêque de Crémone à partir de 962 et est notamment l'auteur de l'»Historia Ottonis «. 
aussi un changement de la nationalité de l'empereur et de ce fait un changement des fondements juridiques qui réglaient sa condition quant au droit et donc son élection. Il est évident que cette vision de la translatio Imperii servait à ériger la royauté française en véritable successeur des empereurs de la maison de Charlemagne.

Maimbourg rapporte que, au début, l'assemblée chargée d'élire le nouvel empereur était assez vaste, comprenant non seulement des représentants des villes, mais aussi des Italiens ${ }^{79}$. Pourtant, ce n'est pas la véracité de ce récit sur la composition des premières assemblées électorales qui doit retenir notre intérêt, mais la façon dont, selon Maimbourg, on en aboutit à la constitution du collège des sept princes, jouissant à titre exclusif du droit d'élire l'empereur. Cela se fit en plusieurs étapes: Maimbourg s'en remet à plusieurs auteurs médiévaux, en particulier à Otton de Freising, ainsi qu'à Windeck et à Baronius, pour établir le fait que la forme de l'élection impériale subit de profondes modifications à partir d'Henri $\mathrm{V}$, dans la mesure où les princes les plus puissants, tenant des offices de l'Empire, profitèrent de leur autorité pour ne plus accorder aux autres états qu'un droit de présenter des candidats et d'approuver, le cas échéant, l'élection de l'empereur, si leur choix s'était porté sur un candidat qui n'avait pas été nommé par les états.

Selon Maimbourg, un autre changement s'opéra après l'avènement de Conrad III, l'élection étant désormais réservée aux seuls feudataires de l'Empire; après l'élection de Frédéric Ier, le droit d'élire l'empereur fut restreint aux seuls Allemands, comme Maimbourg le rapporte sur la foi d'une épître signée par Innocent III ${ }^{80}$.

Bien qu'il ne discute pas en détail de ces étapes qui aboutirent successivement à la restriction du corps des états participant à l'élection impériale ${ }^{81}$, il convient de noter que Maimbourg savait bien que ni la forme de l'élection ni la composition du corps électoral n'avaient été fixées avant le XIII ${ }^{\mathrm{e}}$ siècle. En effet, Maimbourg s'en remet à la chronique d'Ursberg ${ }^{82}$, qui rapporta en 1210 que la plupart des princes d'Allemagne avaient participé à l'élection de Frédéric II $^{83}$. Ajoutant foi au récit d'Albert de Staden ${ }^{84}$, de même qu'à celui de Martinus Polonus ${ }^{85}$, Maim-

79 Maimbourg fonde ses observations au sujet de ces assemblées sur Conring, Wicquefort et Baronius, ainsi que sur plusieurs auteurs allemands médiévaux.

80 »enerabilem de electione «, cf. MaImbouRG, Histoire de la décadence de l'Empire, p. 105-107.

81 À ce sujet, nous renvoyons le lecteur aux ouvrages cités ci-dessus et surtout à l'excellente étude de BECKER, Kurfürstenrat.

82 Cf. Ursberg, Die Chronik des Propstes Burchard von Ursberg.

83 Cf. Maimbourg, Histoire de la décadence de l'Empire, p. 107-108.

84 Les »Annales Stadenses « ont été publiés dans: Monumenta Germaniae Historica (MGH). Scriptores (SS), vol. 16, éd. par Georg Heinrich PERTZ, Hanovre 1859 (réimpression Leipzig 1925), p. 271-379. Cf. Gerda MAECK, Die Weltchronik des Albert von Stade. Ein Zeitzeugnis des Mittelalters. Studien zur Geschichtsschreibung Alberts von Stade, Lehrte 2001.

85 La »Chronique « de Martinus Polonus (ou Martin de Pologne, Martin von TropPau) a été publiée dans: MGH. SS, vol. 22, éd. par Georg Heinrich PERTZ, Hanovre 1872 (réimpression Leipzig 1928), p. 377-475. Albert et Martin soutenaient la théorie des archioffices, cf. BrAUN, Ein italienischer Blick, p. 73. 
bourg estime que ce furent les mêmes princes allemands qui avaient constitué l'assemblée électorale pour l'élection de Frédéric Ier qui convinrent de limiter le droit d'élection aux sept tenants d'un archioffice impérial ${ }^{86}$. On peut noter qu'un traité manuscrit des électeurs et de l'élection impériale qui date des années 1650 , et qui est aujourd'hui conservé à la Bibliothèque nationale ${ }^{87}$, nie à juste titre l'idée qu'il y ait eu un lien entre le droit de vote et la possession des archioffices au XIII siècle. Pourtant, les deux récits convergent en ce qu'ils considèrent que le nombre de sept électeurs fut fixé au XIII' siècle. Tout en acceptant l'idée selon laquelle les sept électeurs apparaissent pour la première fois chez Albert et Martin, entre 1210 et 1240, Maimbourg persiste dans l'opinion que l'instauration définitive du collège électoral fut l'œuvre de Charles IV. C'est aussi à la Bulle d'or promulguée par cet empereur que Maimbourg fait remonter l'origine du titre d'électeur.

Or, s'il admet que Grégoire V ne créa pas le collège électoral, Maimbourg, en tant qu'auteur ecclésiastique, refuse-t-il à la papauté tout rôle dans le processus de sa création? Comme nous l'avons vu, cette question n'était pas sans conséquences politiques au XVII e siècle, puisque la Curie en déduisait son droit de confirmation des empereurs récemment élus ainsi que celui d'approuver tout changement dans la composition du collège électoral.

En effet, Maimbourg ajoute foi à Bellarmin, à Baronius et à d'autres autorités qui prétendent que le droit d'élection fut instauré par la papauté, en particulier par Innocent III ${ }^{88}$. Mais Maimbourg n'étend pas l'intervention pontificale à tous les aspects de l'élection impériale, car il distingue deux sortes de droits d'élection: le premier concernait l'élection de l'empereur en tant que souverain de la monarchie d'Allemagne; le second était fondé sur sa prérogative exclusive d'être couronné par le pape et de porter le titre impérial. En ce qui concerne l'élection de l'empereur en qualité de souverain d'Allemagne, Maimbourg réfute l'idée d'une quelconque dépendance de celle-ci vis-à-vis de la papauté: l'élection du souverain d'Allemagne ne dépendait pas plus du pape que celle du roi de Pologne, mais elle avait été accordée aux électeurs par délégation de tous les ordres et feudataires de l'Empire; cette délégation remontait au temps de Frédéric II ${ }^{89}$. À l'inverse, le droit exclusif au couronnement et au titre impérial avait une origine papale. Selon Maimbourg, »il est tout manifeste « que les papes ont accordé aux électeurs la prérogative en fonction de laquelle l'empereur qu'ils élisent est le seul à avoir droit

86 Cf. Maimbourg, Histoire de la décadence de l'Empire, p. 108-109.

87 BNF, F.fr. 18987

88 Cf. Maimbourg, Histoire de la décadence de l'Empire, p. 109 et 110 (citation): »le droit d'élire les Empereurs est émané du Saint Siége«.

89 Cf. ibid., p. 110-111: »dans les Royaumes électifs, c'est de Dieu seul, indépendemment des Papes, que les Estats tiennent le droit qu'ils ont d'élire un Roy [...]. Ainsi le droit que quelques Princes Allemans ont encore aujourd'huy d'élire le Chef $\&$ le Souverain de ce qui leur reste de leur ancienne Monarchie, \& de tout ce qui en dépend, ne leur est venu que des Estats \& de l'Assemblée des Princes \& des Feudataires, qui, d'un commun consentement, le leur ont attribué sous l'Empire de Frideric II $\ll$. 
au couronnement et au titre d'empereur, puisque les papes "se sont obligez euxmesmes à couronner, \& à proclamer Empereurs les Rois de Germanie«, à moins que l'élu ne soit hérétique ou païen. Au fil du temps, le couronnement ne fut plus considéré comme indispensable sans pour autant que le fait de renoncer au voyage à Rome portât préjudice à l'empereur élu ${ }^{90}$.

$\mathrm{Si}$, selon Maimbourg, la papauté joua effectivement un rôle dans l'instauration des sept électeurs du Saint Empire romain germanique, il réfute expressément l'hypothèse selon laquelle le collège électoral aurait été créé par Grégoire $\mathrm{V}$ ou par Otton III. Le fait que Maimbourg insère cette digression dans son chapitre sur l'année 996 prouve cependant que cette théorie avait toujours certains adeptes en 1679. Pour sa part, tout en concédant que de nombreux auteurs médiévaux et modernes la soutenaient, Maimbourg relève d'emblée la faiblesse de cette théorie: il n'y avait aucune preuve contemporaine d'une telle création, les premiers auteurs qui évoquent une constitution papale ou impériale ayant vécu trois quarts de siècle après la mort des protagonistes ${ }^{91}$. De toutes les hypothèses qui existent sur l'origine du collège électoral, Maimbourg tient celle-ci pour la plus »insoustenable«, car elle ne peut invoquer aucune pièce d'archives, ni aucun document recopié dans les diverses compilations d'acta publica, ni même aucun témoignage authentique et contemporain de cette instauration supposée en 996.

Étant donné que jusqu'au temps de Frédéric II les successeurs d'Otton III furent élus par des diètes ou par des assemblées princières générales, Maimbourg est d'avis que le collège électoral ne fut créé qu' après 1210: »Ainsi tout ce qu'on a dit sur cela de Grégoire \& d'Otton, n'est qu'une pure vision, semblable à ces songes qui s'évanoûissent aussitost qu'on les veut examiner «. Maimbourg réfute en particulier le raisonnement de Baronius selon lequel Otton III aurait perdu l'espoir d'avoir un prince héritier au moment de convenir avec le pape d'un règlement pour l'élection impériale. Tout en professant son estime pour ce cardinal, c'est encore à Baronis que Maimbourg s'attaque au sujet du concile de Lyon I, où - d'après Baronius - Innocent IV aurait créé les sept électeurs; or, Baronius reprit à son compte une digression insérée par Mathieu Paris dans les actes de ce concile, digression qui traite justement des électeurs de l'Empire, »\& dans laquelle [l'auteur] débite des fables \& des faussetez toutes visibles«.

Réfutant strictement la création des électeurs en 996, Maimbourg penche pour l'instauration de leur collège entre 1210 et 1240 ; il a tiré ce terminus ante quem d'Albert de Staden. C'est pourquoi il estime que l'institution des sept électeurs

${ }^{90}$ Cf. ibid., p. 111 (citation) et p. 112. Maimbourg se fonde encore sur Innocent III, »Venerabilem de electione $\ll$.

91 Cf. ibid., p. 112-113: »C'est une chose étrange, que la pluspart des Auteurs modernes, \& mesme des anciens, mais pourtant de ceux qui n'ont écrit que plus de soixante $\&$ dix ans aprés la mort de Grégoire V. \& d'Othon III. se sont mis dans l'esprit, les uns que ce fut ce Pape, \& les autres que ce fut cét Empereur Othon III. qui donna ce droit aux sept Electeurs par une Constitution, à laquelle, en faisant valoir leurs conjectures, ils font dire, quoy qu'ils ne l'ayent jamais veûë, tout ce qu'il leur plaist«. 
n'a pas été faite au concile de Lyon I (1245) ni, a fortiori, de l'autorité du pape Grégoire X, au concile de Lyon II, en 127492 .

Selon Maimbourg, trois papes peuvent avoir déféré aux électeurs le droit que le roi de Germanie, élu par ces derniers, avait sur la couronne impériale ${ }^{93}$ : Jean XII (sous lequel la dignité impériale fut unie à celle de roi de Germanie), Léon VIII (lequel accorda à Otton Ier le droit d'élire un successeur à la dignité impériale) et Gerbert (selon Naucler, il était l'auteur d'un décret conservé aux archives d'Aquilée, donnant aux Allemands le droit d'élire l'empereur et confirmant en particulier l'élection du successeur d'Otton III). D'après le sentiment de Maimbourg, qui ne passe pas sous silence ses doutes sur ces attributions, c'est Jean XII qui fut à l'origine du droit d'élection, donc un pape du temps d'Otton Ier. Mais Maimbourg ne pense pas pour autant que le collège électoral fut instauré par ce pape; au contraire, il s'agit seulement du droit à la dignité impériale ${ }^{94}$. Selon Maimbourg, le collège des sept électeurs fut créé entre 1210 et 1240 . Ainsi, il en conclut que ce collège ne fut institué que deux siècles après les décès d'Otton III et de Grégoire $\mathrm{V}$, que certains historiens et juristes ont tenus pour les fondateurs du collège électoral $^{95}$.

En conclusion, il faut donc noter que la fable qui situait l'origine des sept électeurs au temps de Grégoire V et d'Otton III a bien trouvé quelques adeptes en France, même après les traités de Westphalie, mais qu'elle n'y faisait point l'unanimité; au contraire, des auteurs de la deuxième moitié du XVIIe siècle, tels que Maimbourg, connaissant bien la discussion sur ce point - à laquelle avaient contribué notamment les auteurs allemands et italiens - la remirent sérieusement en question. Contrairement à la curie romaine ${ }^{96}$, les Français, tout en n'y étant pas complètement insensibles, n'accordèrent plus guère de crédit à cette fable après 1648 .

92 Cf. ibid., p. 113-116, citations p. 113, 115.

93 Il ne s'agit donc pas nécessairement d'un concours de la papauté à la création du collège électoral ou à la fixation du nombre d'électeurs.

$94 \mathrm{Cf}$. son raisonnement sur ce problème, MAIMBOURG, Histoire de la décadence de l'Empire, p. 116-119. D'ailleurs, cela résulte clairement de ses remarques sur Léon VIII; d'après l'exposé de Maimbourg, le droit d'élire un successeur à la dignité impériale, accordé par Léon VIII à Otton Ier, put être transmis aux états d'Allemagne: »Or comme aprés la mort d'Othon III. qui mourut sans enfans, tout le droit de cét Empereur fut dévolu aux Estats qui luy succederent dans la Souveraine autorité, \& qui subsistant toûjours, ne meurent jamais: il est certain qu'ils recueillirent aussi ce droit d'étire celuy qui seroit Empereur; ce qu'ils résignerent depuis aux sept Electeurs«.

95 Cf. ibid., p. 119, à la fin de cette digression: »je crois que le plus seûr est de s'en tenir à ce que j'ay dit du Pape Jean XII. que je ne doute nullement qui ne soit la vraye origine de ce droit d'élection à la dignité Imperiale, qui des Estats de l'Empire est passé aux sept Electeurs plus de deux cens ans aprés la mort de Grégoire V. \& d'Othon III «.

96 Cf. LUTZ, Roma e il mondo germanico. Nos propres recherches sur l'image du Saint-Empire à Rome, non encore publiées, ont montré que non seulement au XVIIe, mais même au XVIIIe siècle, la curie romaine n'abandonna pas complètement cette vision de l'origine du collège électoral. 


\section{Jean Heiss et l'origine des électeurs (1684)}

Dans son »Histoire de l'Empire«, publiée en 1684 (et rééditée huit fois jusqu'en 1733), Jean Heiss, originaire de Clèves en Allemagne, aborde à deux reprises le problème de l'origine des électeurs: tout d'abord dans sa partie chronologique, en évoquant l'année $999^{97}$, puis dans sa partie thématique, au début du livre $\mathrm{V}$, qui est consacré aux électeurs ${ }^{98}$. Il faut bien admettre que les explications de la partie chronologique sont pour le moins ambiguës. Heiss résume d'abord les résolutions qu'Otton III aurait prises dans un décret au sujet du droit d'élection; le droit de vote aurait été réservé aux seuls princes allemands, et l'autorité papale aurait été limitée au seul droit de couronner l'empereur ${ }^{99}$. Ensuite, Heiss rapporte la fable des électeurs, sans se prononcer sur sa véracité ${ }^{100}$.

En revanche, dans son livre sur les électeurs, Heiss s'explique très clairement, et, à un détail près, ses explications sont correctes. Selon Heiss, les princes qui élisaient l'empereur prirent le titre d'électeurs pendant l'interrègne qui suivit la mort de Frédéric II de Hohenstaufen. Et d'ajouter: »Ils s'y autoriserent d'autant plus facilement, qu'êtans [sic] les plus considerables \& puissans de l'Empire, ils se rendirent arbitres du gouvernement; en sorte qu'ils nommerent de leur chef, Rodolphe I. \& les Empereurs suivans, sans aucune contestation de la part des autres Etats, quoi qu'ils ne fussent fondez que sur l'usage«. Selon Heiss, cette pratique fut institutionnalisée et érigée en loi fondamentale de l'Empire par la Bulle d'or. La séparation des électeurs pour l'élection de l'empereur entraina la formation de leur collège comme organe discutant des affaires générales de l'Empire ${ }^{101}$.

Si ces explications au sujet de l'origine du collège électoral sont en principe conformes à l'opinion de la plupart des juristes allemands du XVII ${ }^{e}$ siècle et si elles correspondent également à l'état actuel de la recherche, Heiss commet une erreur en prétendant qu'après la mort de Lothaire III, c'est-à-dire en 1138, les princes de l'Empire décidèrent à Coblence de députer trois électeurs ecclésiastiques et quatre électeurs séculiers (un roi, un comte palatin, un marquis et un duc) afin d'élire son successeur ${ }^{102}$. En réalité, l'élection de Conrad III fut contestée, et

97 Cf. HeIss, Histoire de l'Empire (édition de 1685), t. I, p. 110-111.

98 Cf. ibid., t. II, p. 56-58.

99 Cf. ibid., t. I, p. 110-111.

100 Cf. ibid., p. 111: »Il y a plusieurs Historiens, qui asseurent que le Pape \& l'Empereur pour mieux asseurer l'Empire à la nation Allemande, reduisirent ensuite les Electeurs au nombre de sept, mais que cela soit vray ou non, il est au moins certain, que depuis le dernier des Empereurs François, les Princes d'Allemagne estoient en possession du droit d'élire l'Empereur, \& de le choisir de leur propre païs. Et c'est proprement ce qu'Othon confirma, \& dont il ordonna l'execution pour l'avenir «.

101 Cf. ibid., t. II, p. 57 et 58 (citation). Et d'ajouter (ibid.): »Les Electeurs ayans ainsi commencé depuis le regne de Frideric II. à s'assembler separément pour l'élection, prétendirent aussi avoir droit de tenir à part leurs conferences pour les autres affaires de l'Empire, sans avoir égard aux protestations que les autres Princes, $\&$ les villes Imperiales, faisoient contre cette separation «.

102 Cf. ibid., p. 57. D'ailleurs, Heiss écrit »Lothaire II« au lieu de Lothaire III. Lothaire III (1075-1137) avait été élu en 1125. Son successeur, Conrad III (1095-1151), fut élu en 1138. 
l'assemblée qui l'avait élu à Coblence, à l'instigation de l'archevêque Albero de Trèves, est encore aujourd'hui considérée comme irrégulière par les historiens. Or, selon Heiss, les mêmes électeurs qui avaient été députés en 1138 élirent également les empereurs suivants jusqu'à Frédéric II, après la mort duquel ils se nommèrent électeurs ${ }^{103}$.

Nous voyons donc que, dans les ouvrages français sur l'histoire du droit public allemand, des points obscurs persistèrent à l'égard de la datation et de l'explication de l'instauration des sept électeurs ${ }^{104}$. Ainsi, Heiss évite en particulier de se prononcer clairement contre les auteurs qui l'attribuaient à Grégoire $\mathrm{V}$ ou à Otton III, et, en parlant de l'exclusion des princes italiens du droit d'élection, il reprend même à son compte l'un des principaux points de cette fable ${ }^{105}$.

\section{Conclusion}

En étudiant un problème précis, en l'occurrence l'origine des électeurs, ce chapitre montre que les auteurs qui écrivaient en français sur le droit public allemand s'inscrivaient plus largement dans un débat européen. Les auteurs médiévaux et la plupart des auteurs modernes qui sont cités dans les ouvrages français sont évo-

103 Cf. ibid., p. 57-58.

104 Dans la première moitié du XVIII e siècle, l'auteur d'une »Introduction à l'histoire de plusieurs Estats de l'Europe« prétend que les sept électeurs n'ont été instaurés que par la Bulle d'or de Charles IV et que, seulement à partir de la diète de Francfort, en 1581, »les sept électeurs commencèrent à faire un corps particulier distingué des princes de l'Empire audessus desquels ils n'avoient eu depuis la Bulle d'or d'autre prérogative que celle de concourrir à l'élection de l'Empereur «, bibliothèque de la Sorbonne, mss. 942-943, ici ms. 942 fol. 12-12' (citation fol. 12'). Toutefois, en général, cet auteur est bien renseigné. Son œuvre ( 2 tomes) est constitutée d'une introduction à l'histoire des »Empereurs d'Allemagne « (ms. 943 fol. 33), qu'il ne considère pas comme les successeurs des empereurs romains (fol. 1), de deux mémoires concernant la justice dans l'Empire et la matricule impériale ainsi que de neuf mémoires relatifs aux neuf princes électeurs (les onze mémoires datent de janvier et de février 1723). L'auteur d'un mémoire rédigé sous le règne de l'empereur Joseph Ier $^{\mathrm{e}}$ intitulé »De l'élection de l'Empereur. De l'origine des électeurs de l'Empire. De la Bulle d'or de Charles IV. De la capitulation de Joseph I. frère â̂né de l'Empereur dernier mort« (IF, Fonds général, ms. 1687 fol. 21-31') estime que les électeurs sont apparus au temps de Frédéric II: "Le collège électoral n'a pas été institué par l'Empereur Othon III. ni de son tems, ni par les Papes de son tems, ou de celui d'Othon IV. comme l'ont prétendu plusieurs historiens ecclésiastiques. Les élections ne furent donc proprement que des confirmations du droit de succession « (fol. 22-22'). Et d'ajouter: »Si le collège électoral a été réduit au nombre de sept électeurs, avant la Bulle d'or? Il est prouvé par plusieurs détails d'histoire tirés des meilleurs auteurs $1^{\circ}$ que d'abord tous les princes avoient droit de se trouver aux élections. $2^{\circ}$ Que la qualité d'électeur n'a commencé d'être connue que sous Frédéric II. $3^{\circ}$ Qu'elle s'est faite une dignité particulière peu à peu. $4^{\circ}$ Que les électeurs se sont saisis de ce droit par une coutume insensiblement introduite. $5^{\circ}$ Que leur nombre et leur droit n'ont été réglés par aucune loy expresse que du tems de Charles IV en 1356 « (fol. 23-23').

105 En 1696, l'auteur d'une note intitulée »Mémoires concernans le landtgraviat d'Alsace« affirmait toujours que le collège des sept électeurs avait été institué par Otton III en 994 ou en 996, copie de cette note: AE, MD Alsace 27 fol. 144-147'. 
qués également dans les livres allemands et italiens. Dans le cadre des études imagologiques, il nous paraît donc particulièrement important de ne pas limiter l'étude des sources à la confrontation des connaissances des auteurs anciens aux résultats de la recherche récente, mais de replacer les différents discours 'nationaux « dans leur contexte européen, puisqu'ils faisaient partie intégrante d'un débat supranational. Il importe donc d'analyser la dépendance respective de ces discours français, italien, allemand et autres et d'étudier leurs échanges mutuels. 
